\title{
Rapid Autoxidation of Phenol Derivative under Atmospheric Pressure of Molecular Oxygen
}

\author{
Seokwon Jung and Seung Wook Ham \\ Department of Chemistry, Chung-Ang Lniversity, Seoul 156-756, Korea. "E-mail: swhamacatuackr \\ Received February 8, 2007
}

Key Words : Phenol. Autoxidation. Electron transfer mechanism. Cyclopropyl radical

The oxygenation of phenolic and naphtholic conpounds has been investigated in great details, partly due to the attractive biological activity of this class of molecules. ${ }^{1.8}$ It is generally believed that the oxygenation is occurred via the singlet oxygen generated by chemical means. It is well known that triplet oxygen does not react readily with most organic molecules because of the spin restriction. However. several reports pointed out the possibility of hydroperoxidation by the triplet oxygen. ${ }^{4,68}$ We have recently published results on the mechanism studies of base-catalyzed oxygenations of phenols and naphthole. ${ }^{9}$ In current project. we used 4-cyclopropyl substituted 2,6-di-t-butylphenol 1 as a new mechanistic probe to investigate the reaction of molecular oxygen and phenolate anion 2 . We suggested that the reaction of phenoxyl anion 2 with molecular oxygen to form the phenoxy radical and then to from superoxide by electron transfer could be a process happened in the biological system. ${ }^{9}$ As a consequence of this process. the corresponding hydroperoxide 3 was observed under atmospheric pressure of oxygen.
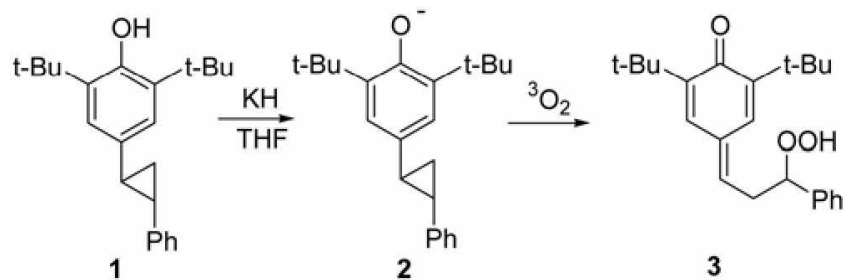

In the course of preparation of phenyl substituted cyclopropane derivative. we found that compound 1 even in the solid state slowly decomposed in air at roon temperature. Compound 1 is a ground singlet, the autoxidation reaction of 1 with molecular oxygen was conveniently monitored by ${ }^{1} \mathrm{H}$ NMR using $\mathrm{CDCl}_{3}$ as a solvent. The resonance peaks which were later assigned belonging to compound + immediately appeared. The peaks corresponding to the starting material

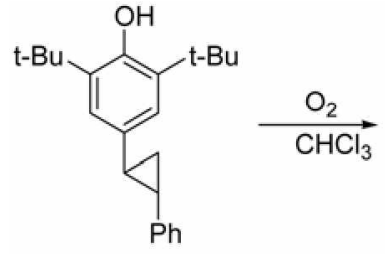

1

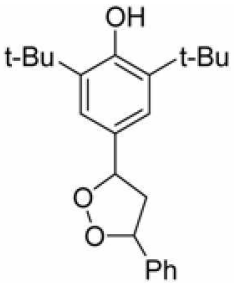

4 were completely disappeared within $30 \mathrm{~min}$. The product 4 was purified by chromatography in $90 \%$ yield. ${ }^{10}$

Two possible mechanisms are proposed for the autoxidation reaction. One is a charge transfer mechanism, where the electron-rich phenol or phenoxyl anion interacts with $\pi$ orbital of molecular oxygen to afford a triplet charge transfer complex. and then the complex undergoes intersystem crossing. ${ }^{4}$ It has been previously reported that reaction of $1.1,2.2-$ tetraanisy lcyclopropane with both themally and photochemically generated singlet oxygen afforded the corresponding 1.2-dioxolane by $\left[\hat{\pi}^{2}+\pi^{2}+\sigma^{2}\right]$-cycloaddition. ${ }^{11}$ The selfsensitized autoxidation in the presence of light and molecular oxygen, but without requirement for a photosensitizer was also reported. ${ }^{12}$ Therefore, we conducted the oxygenation reaction of compound 1 with singlet oxygen. Thus, when 1 was photoosygenated with tertaphenylporphine (TPP) as a singlet oxygen sensitizer in $\mathrm{CHCl}_{3}$, compound 4 was obtained quantitatively. To examine whether singlet oxygen was really produced via energy transfer, we then carried out the control oxygenation reactions. However, when the reaction was carried out under atmospheric pressure of triplet oxygen in the absence of light, the oxygenation was not inhibited and the reaction rate was not changed. Addition of excess 1.4-diazbicyclo[2,2.2] octane(DABCO), a known singlet oxygen quencher, to the reaction mixture also did not have any influence. These experiments suggested that singlet oxygen was not an oxidizing agent.

Electron transfer mechanism is an altemative pathway for autoxidation. The organic compounds react with molecular oxygen to give the organic radical and the superoxide by one-electron transfer. ${ }^{13}$ The radical then traps oxygen to yield the oxygenated products. Scheme I shows the possible pathway for the formation of 1,2-dioxolane from compound 1 by electron transfer. For the electron transfer from phenols to molecular oxygen. the relative one-electron reduction potential of phenols and molecular oxygen controls the equilibrium. Since the redox potential for molecular oxygen to superoxide ion is $-0.5 \mathrm{~V}$ is $\mathrm{NHE}^{1+}$ in aprotic solvent and the reduction potential of $t$-butyl substituted phenol is 1.l$1.5 \mathrm{~V}^{15}$ which suggests that the direct electron transfer of phenols to oxygen (Path $A$ ) is an unfavorable reaction by the overall potential by $1.6-2.0 \mathrm{~V}$.

To overcome the thermochemical weakness. we believe that the reduction of molecular oxygen by the equilibrated anion of the model 1 might produce superoxide anion and 
<smiles>CC(C)(C)c1cc(C2CC2c2ccccc2)cc(C(C)(C)C)c1O</smiles>

1

Path $\mathrm{A} \mathrm{O}_{2}$<smiles>CC(C)(C)C1=CC(=C(C(C)(C)C)C(C)(C)C)C(=O)C(C(C)(C)C)=C1</smiles><smiles>CC(C)(C)c1cc(C2CC2c2ccccc2)cc(C(C)(C)C)c1[O-]</smiles>

2

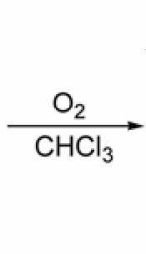<smiles>CC(C)(C)c1cc2cc(cc1=O)C2c1ccccc1</smiles><smiles>CC(C)(C)C1=CC(=CCCc2ccccc2)C=C(C(C)(C)C)C1=O</smiles>

5<smiles>CC1OC(c2cc(C(C)(C)C)c(O)c(C(C)(C)C)c2)CC1c1ccccc1</smiles><smiles>C[C@H](C1=CC(=CCC(O)c2ccccc2)C=C(C(C)(C)C)C1=O)C(C)(C)C</smiles>

3

Scheme 1

phenoxyl radical 5 as shown in the previous studies. ${ }^{8}$ Fast ring-opening of cyclopropylcarbinyl radical 5 followed by addition of molecular oxygen to the radical intermediate 6 yields a peroxyl radical which abstracts a hydrogen to form hydroperoxide 3 and then converts to the product + via the 1,6-addition. The cis-configuration between two aromatic moieties was unambiguously determined by 2D-ROESY NMR analysis (Data not shown). Phenol and 2,6-di-t-butyl 4-methylphenol shows no reactivity under the atmospheric pressure of triplet oxygen. At the B3LYP/6-31+G(d) level. the calculated gas-phase protonation energies for phenoxyl anion and anion 2 are $351.0 \mathrm{kcal} / \mathrm{mol}$ and $340.8 \mathrm{kcal} / \mathrm{mole}$. respectively ${ }^{10}$ Interestingly, compound $\mathbf{2}$ appears to be more acidic than phenol owing to the phenylcyclopropyl group. These experimental observation and theoretical consideration seen to suggest that our mechanistic pathway is indeed operative.

For the consideration of the electron transfer from phenoxyl anions to oxygen. one-electron reduction potential of phenoxy radical is about $-0.29 \mathrm{~V}$ is SCE in $\mathrm{CH}_{3} \mathrm{CNN}^{15}$ and the overall potential for electron transfer of phenoxide anion to oxygen is about $0.2 \mathrm{~V}$. This potential is not as high as that for electron transfer of phenols to oxygen. but still implies the unfavorable reaction with the free-energy change of about $3 \mathrm{kcal} / \mathrm{mol}$. However. ab initio calculation indicated that the Gibbs free energy change of rearrangement from radical 5 to radical 6 is exothermic by $-2.98 \mathrm{kcal} / \mathrm{mol}$. indicating that the ring-opening of cyclopropyl radical is favorable. Moreover. our model undergoes a partial combustion with molecular oxygen in the course of oxygenation and more than ample energy is available to overcome their electro-potential weakness for the phenoxyl radical and superoxide formation

In summary the autoxidation of organic electron-rich phenols proceed at high oxygen pressures and elevated temperatures to yield the corresponding hydroperoxide at slow rates. The origin of this chemistry appears to involve an unfavorable electron transfer from the substrates to oxy'gen.
In the case of cyclophenyl derivative 1, the acidity of 1 and preferable ring opening of cyclopropyl radical to homoallylcarbinyl radical initiates the rapid autoxidation at mild conditions.

Acknowledgements. This work was supported by the Chung-Ang University (2006).

\section{References and Notes}

1. Nishinaga, A.: Itahara, T.; Matsuura, T. Chem. Lett. 1974. 667.

2. Kemal. C. Chan. T. W. Bruice, T. C. J. Am. Chem. Soc, 1977, 99. 7272 .

3. Demmin. T. R.: Swerdloff. M. D.: Rogic. M. M. J. Ant Chent. Soc. 1981. 103.5795

4. Matsumoto. S.: Matsuo. M.: Iitaka. Y. J. Ong. Chem. 1986. 5l. 1435.

5. Cilliers, J. L.; Singleton. V. L. J. Agric. Food Chem. 1990. 38. 1797.

6. Dowd. P.: Ham, S. W. J. Am Chem Soc. $1991,113,9403$.

7. Lambert. C. R.: Black. H. S.: Truscott. I. G. Free Radic. Biol. Med. 1996. 2l. 395

8. Pedrielli. H.: Hedulli. G. H.: Skibsted. L. H. J. Agric. Food Chent 2001. $19,3034$.

9. Lee. D.-H: Son. J. B.; Jung. S.: Song, J.: Ham. S. W. Tetrahedron Lett. $2005,46.7721$.

10. The structure of phenolic diosolane was determined by ${ }^{~} \mathrm{H}$ NMR $\left(800 \mathrm{MHz} . \mathrm{CDCl}, 25^{\circ} \mathrm{C}\right.$ ) analysis which has peaks at $\delta 1.41$ (s. $18 \mathrm{H}$ ). 2.78 (ddd. $1 \mathrm{H} . J=12.5 \cdot 7.7 .6 .7 \mathrm{~Hz}$ ). 3.45 (br dt. $1 \mathrm{H} . J=$ 12.5. $7.4 \mathrm{~Hz}$ ). $5.27(\mathrm{~s}, \mathrm{lH}) .5 .36$ (br t. $1 \mathrm{H}, J=7.6 \mathrm{~Hz}), 5.52(\mathrm{brt}$ $1 \mathrm{H} . d=7.1 \mathrm{~Hz}) .7 .17(\mathrm{~s} . \mathrm{lH}) .7 .34(\mathrm{t}, \mathrm{lH} . J=7.2 \mathrm{~Hz}) .7 .4 \mathrm{l}(\mathrm{t}, 2 \mathrm{H}$, $y=7.2 \mathrm{~Hz})$, and 7.50 (d. $2 \mathrm{H} . J=7.2 \mathrm{~Hz})$. The ${ }^{13} \mathrm{C} \mathrm{NMR}(150$ $\mathrm{MHz} . \mathrm{CDCl}_{3} .25^{\circ} \mathrm{C}$ ) spectrum showed signals at $\delta 33.4 .34 .6 .51 .4$. 83.3.84.4. 124.6. 126.4. 127.7. 128.1. 128.9. 136.3. 140.5. 154.4.

11. Akasaka. T.: Fukuoka. K.: Ando. W. Tetrohedron Lett. 1991. 32. 7695.

12. Ngo. K.-S.; Brown, G. Tetrahedron 1999, 55, 14623

13. Sheldon, R. A.: Kochi. J. K. Hetal-Catalyzed Oxidation of Organic Componds: Academic Press: New York. 1981.

14. Frimer. A. A. The Chemistry of Functional Groups. Penorides: Patai. S. Ed.: Wiley: New York. 1983

15. Grampp. G. Landgraf. S.: Muresanu. C. Electochimica Acta 2004. 49,537 .

16. Zheng. Y.Z.: Bruice. T. C. J. Am. Chem. Soc. 1998. 120. 1623. 